\title{
Speed Controller of Switched Reluctance Motor
}

\author{
D. Kiruthika* and D. Susitra
}

EEE Department, Sathyabama University, India; d.kiruthika.skec@gmail.com, susitradhanaraj@gmail.com

\begin{abstract}
Fuzzy logic control has become an important methodology in control engineering. The paper proposes a Fuzzy Logic Controller (FLC) for controlling a speed of SRM drive. The objective of this work is to compare the operation of P\& PI based conventional controller and Artificial Intelligence (AI) based fuzzy logic controller to highlight the performances of the effective controller. The present work concentrates on the design of a fuzzy logic controller for SRM speed control. The result of applying fuzzy logic controller to a SRM drive gives the best performance and high robustness than a conventional P \& PI controller. Simulation is carried out using matlab simulink.
\end{abstract}

Keywords: P Controller, PI Controller and Fuzzy Logic Controller, Switched Reluctance Motor

\section{Introduction}

In this paper the simulink model for the speed control of switched reluctance motor is carried out using different speed controllers. The simulink models designed for P, PI \& Fuzzy logic controller separately and their performance result is compared. The Switched Reluctance Motor is an electric motor which runs by reluctance torque. For industrial application very high speed of 50,000 rpm motor is used ${ }^{5}$. The speed controllers applied here are based on conventional P\& PI Controller and the other one is AI based Fuzzy Logic Controller. The PI Controller (proportionalintegral controller) is a special case of the PID controller in which the derivative of the error is not used. Fuzzy logic controller is an intelligent controller which uses fuzzy logic to process the input. Fuzzy logic is a many valued logic which is much like human reasoning. In industrial control FLC has various applications, particularly where conventional control design techniques are difficult to apply. A comprehensive review has been done for SRM machine modelling, design, simulation, analysis and control ${ }^{1}$.

\section{Switched Reluctance Motor}

A Switched Reluctance Motor is a singly excited, doubly- salient machine in which the electromagnetic torque is developed due to variable reluctance principle. Both stator and rotor has salient poles but only stator carries winding. As in dc motor the SRM has wound field coils for stator windings. However the rotor has no attached coils or magnets. The projecting magnetic poles of salient pole rotor are made of soft magnetic material. When the excitation is given to the stator windings, a force is created by rotor's magnetic reluctance that bid to align the rotor pole with the adjacent stator pole. In order to preserve sequence rotation, the windings of stator pole switches in a sequential manner with the help of electronic control system so that the magnetic field of rotor pole was lead by the stator pole, pulling towards it ${ }^{9}$.

The rotor pole is said to be "fully unaligned position" when the rotor pole is equidistant from the two adjacent stator pole. This position is called as maximum magnetic reluctance for the rotor pole. In aligned position the rotor poles are fully aligned with the stator poles, this position is called as minimum reluctance of rotor pole. Figure 1 illustrates the 6:4 SRM drive which consists 6 stator poles and 4 rotor poles.

The voltage equation of SRM is given by,

$\mathrm{V}=\mathrm{ri}+\mathrm{d} \Psi / \mathrm{dt}$

$\psi=\mathrm{Li}=\mathrm{N} \varphi$

For $r=0$,

$\mathrm{V}=\mathrm{L} \mathrm{di} / \mathrm{dt}+\mathrm{i}(\mathrm{dL} / \mathrm{d} \theta)(\mathrm{d} \theta / \mathrm{dt})$

${ }^{*}$ Author for correspondence 


$$
\begin{aligned}
& \mathrm{V}=\mathrm{L} \mathrm{di} / \mathrm{dt}+\mathrm{i} \omega(\mathrm{dL} / \mathrm{d} \theta) \\
& \mathrm{T}=1 / 2 \mathrm{i} 2 \mathrm{dL} / \mathrm{d} \Theta
\end{aligned}
$$

This equation determines that the developed torque depends only on current magnitude and $\mathrm{dL} / \mathrm{d} \Theta$ direction but it is independent on current direction ${ }^{7}$.

\section{Block Diagram}

The position of rotor is sensed by the rotor position sensor and it provides its corresponding output to the error detector. Error detector compares reference speed and actual speed to generate error signal which is given to controller block. The controller either fuzzy or PI gives control signal to the converter according to the error signal. The speed of the motor is controlled by the converter through proper excitation of their corresponding windings ${ }^{6}$ (Figure 2).

\section{Speed Control of SRM using Proportional Controller}

The variation between the setpoints and the measured variable sets the manipulated variable in the proportional controller. If the variation is high, the manipulated variable will get affected and it cannot stabilize higher order processes. Large gain is needed to improve the steady state error, when proportional controller is used.

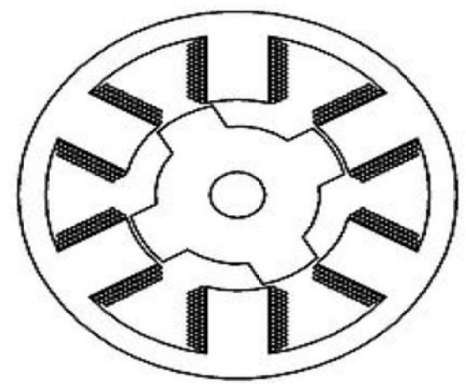

Figure 1. Structure of 3 phase $6 / 4$ SRM.

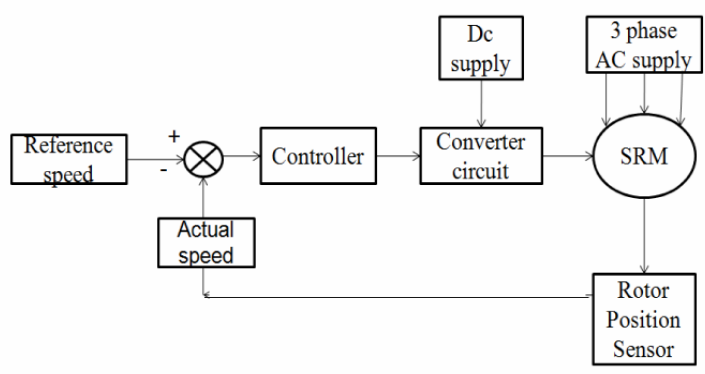

Figure 2. Block diagram of SRM speed control.
If proportional gain is high then the system is said to be unstable. If gain is low, it is said to be stable system. Proportional controller does not eliminate the error just reduces it.

The simulink model is designed for the speed control of switched reluctance motor using P controller and their corresponding output waveform is shown in Figures 3-7. If set speed is 4000, the actual speed displayed is 4003 and the settling time is 0.3 . From speed waveform it can be notified that the proportional controller improves the steady state tracking accuracy and disturbance signal rejection stability.

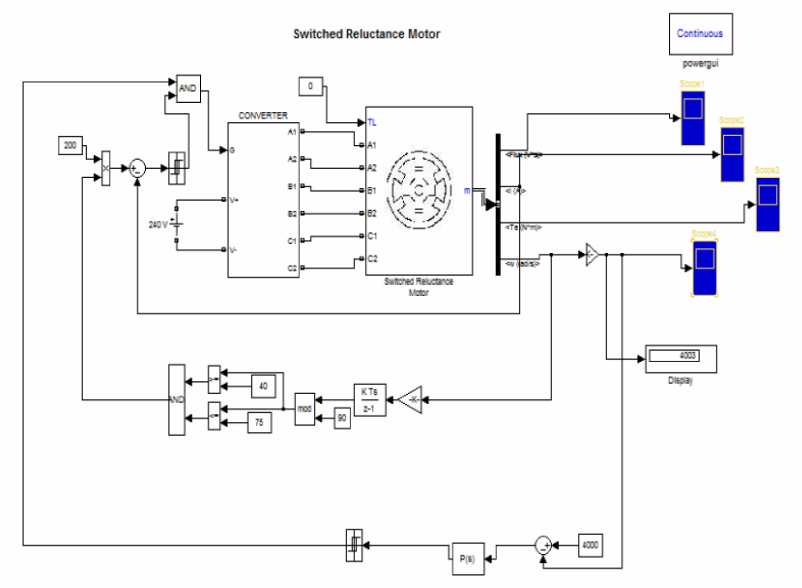

Figure 3. Simulation model using P controller.

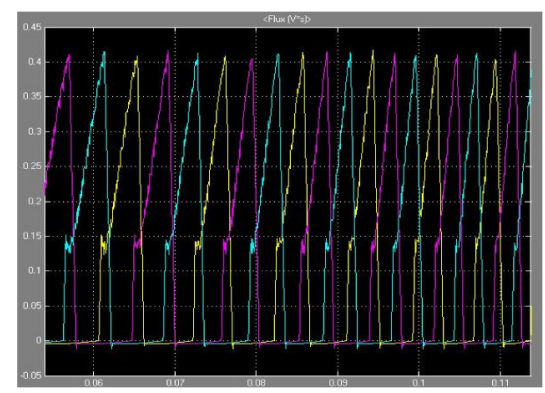

Figure 4. Output flux.

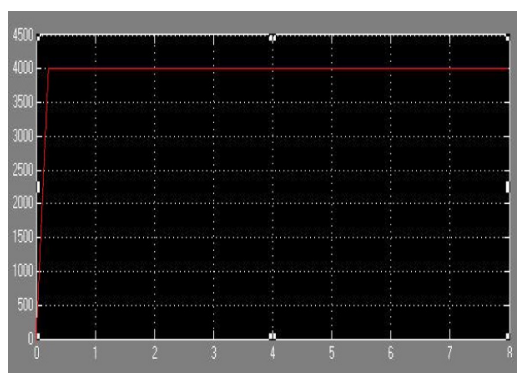

Figure 5. Output current. 


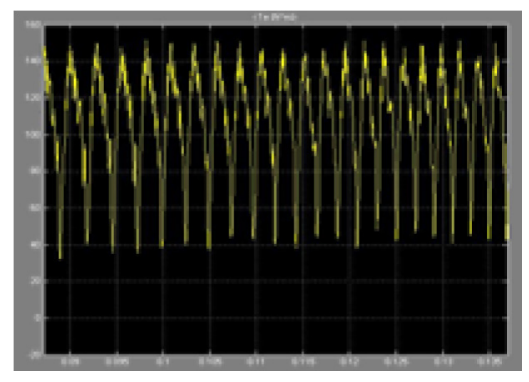

Figure 6. Output torque.

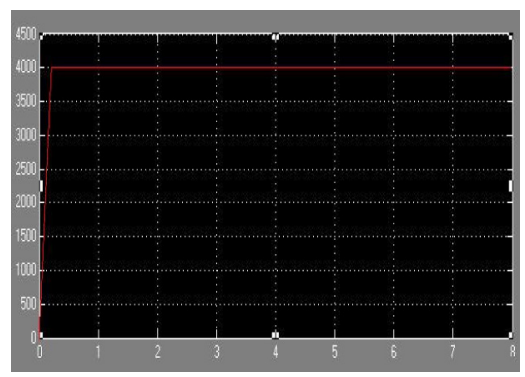

Figure 7. Speed.

\section{Speed Control of SRM using PI Controller}

The combination of proportional and integral terms is essential to refine the speed of the response and also to eliminate the steady state error. By giving feedback to the converter the performance of the PI controller can be improved and it conquers the disturbances. The forced oscillation and steady state error can be eliminated in PI controller during the operation of $\mathrm{P}$ controller and on-off controller respectively.

However, introducing integral mode has a negative effect on stability of the system and in speed response. So that speed response will not increase in PI controller. This problem can be detected by introducing derivative mode. It has the capability to predict the errors and to decrease the reaction time of the controller. If the speed response is not a criteria normally PI controllers are used.

The simulink model is designed for the speed control of switched reluctance motor using PI controller and their corresponding output waveform is shown in Figures 8-12. If set speed is 4000 , the actual speed displayed is 4003 and the settling time is 2 seconds. From speed waveform it can be notified that the introduction of PI controller reduces the steady state error.

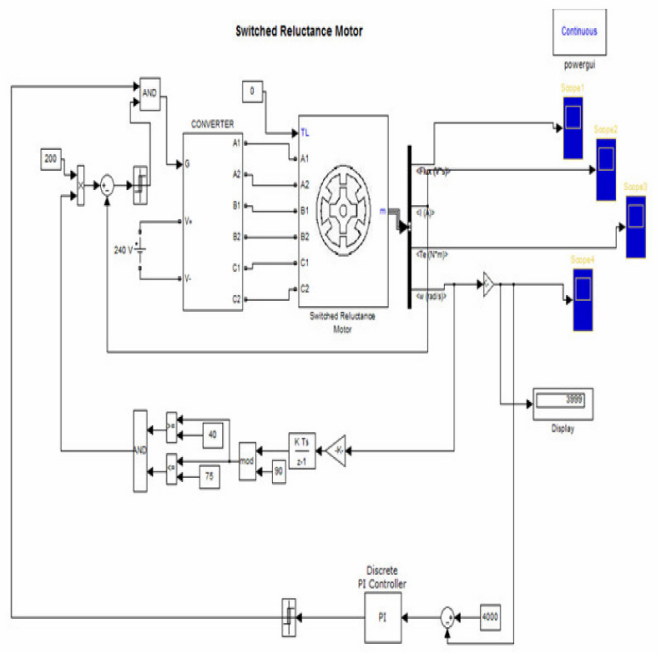

Figure 8. Simulation model using PI controller.

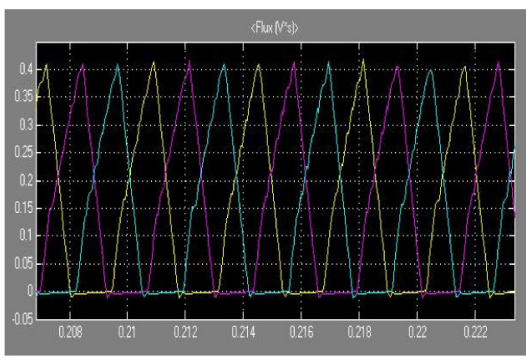

Figure 9. Output flux.

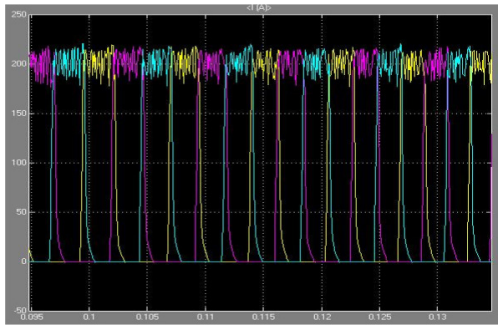

Figure 10. Output current.

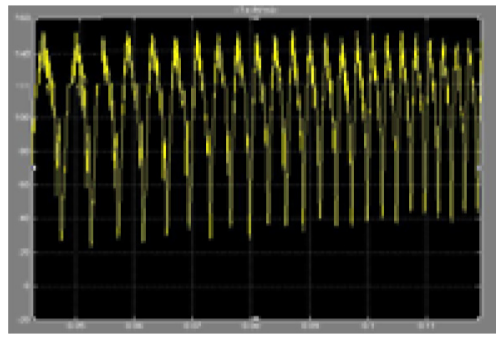

Figure 11. Output torque 


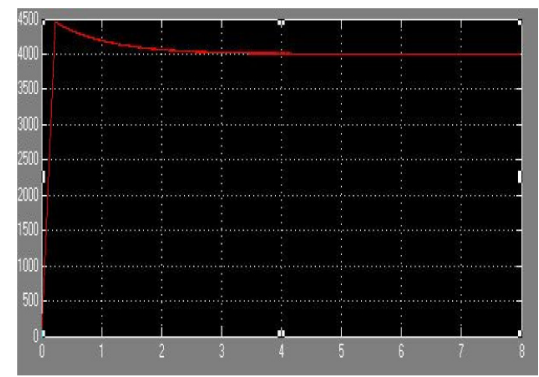

Figure 12. Speed.

\section{Speed Control of SRM using Fuzzy Logic Controller}

Fuzzy logic was proposed by Lotfi Zadeh in 1965, it has various applications in all inventive fields. The merits of fuzzy logic controller are the clarification for a problem can be easily analyzed and the design of the controller can be implemented. The design of fuzzy logic system is not based on the mathematical model of process ${ }^{8}$.

The four main stages in fuzzy logic controller (Figure 13): fuzzification, rule base, inference mechanism and defuzzification as shown in Figure13. The fuzzification is nothing but it comprises the process of transpose crisp values into grades of membership for linguistic terms of fuzzy sets. The transpose from a fuzzy set to a crisp number is called a defuzzification. The inference engine and the knowledge base were the components of an expert system. The knowledge base stores the factual knowledge of the operation of the concern experts. Fuzzy inference engine is the process of calculating from a given input to an output using fuzzy logic. In inference engine, If Then type fuzzy rules converts fuzzy input to the output (Figures 14-17).

Mamdani type fuzzy logic controller is most commonly used in a closed loop control system, because it reduces the steady state error to zero.

The designed fuzzy rules used in this research are given in Table 1. The fuzzy sets have been defined as: negative large (NL), negative medium (NM), negative small (NS), zero (ZR), positive small (PS), positive medium $(\mathrm{PM})$ and positive large (PL) respectively. Many research papers have developed SRM models based on fuzzy logic, hybrid fuzzy and neural techniques ${ }^{2-4}$.

The simulink model is designed for the speed control of Switched Reluctance Motor using Fuzzy logic controller and their corresponding waveform is shown in Figures $18-22$.

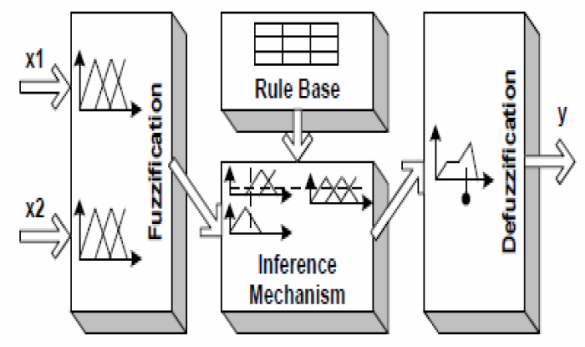

Figure 13. Structure of fuzzy logic controller.

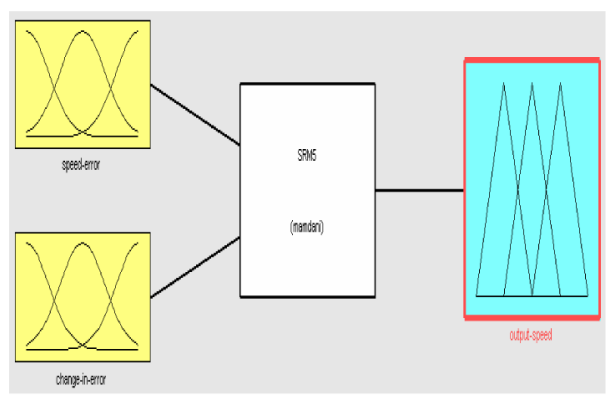

Figure 14. Fuzzy inference system of SRM.

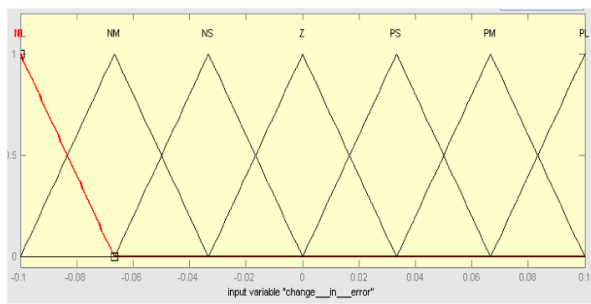

(a)

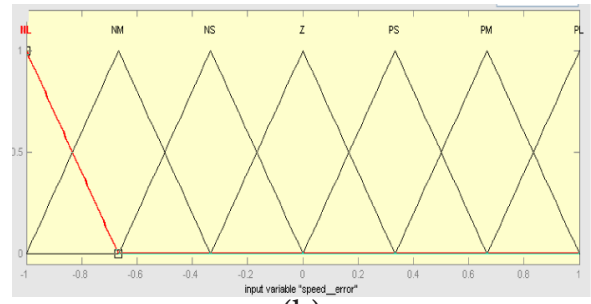

(b)

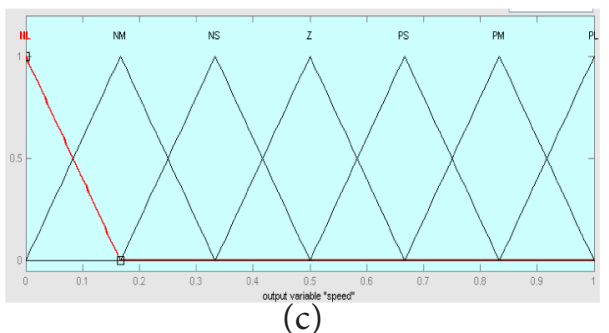

Figure 15. The membership functions of FLC

(a) speed error (b) change in error (c) output speed. 


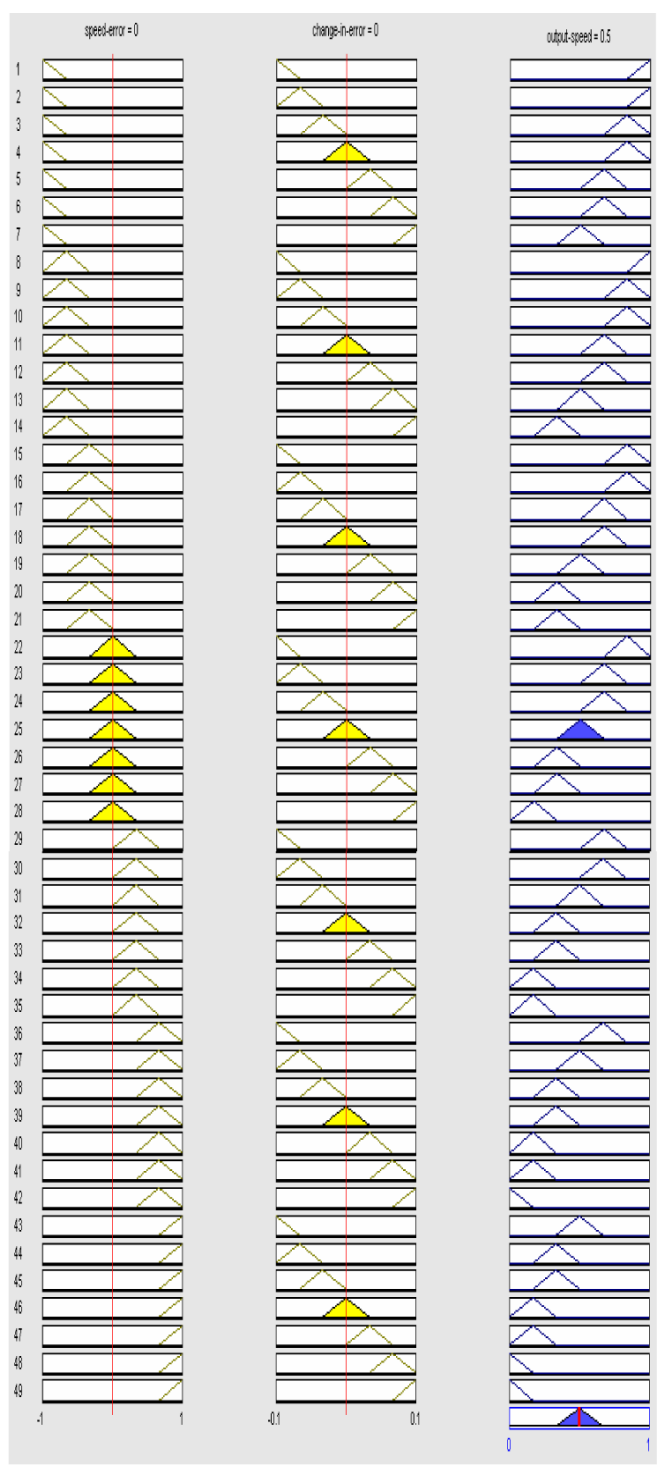

Figure 16. Fuzzy rule viewer.

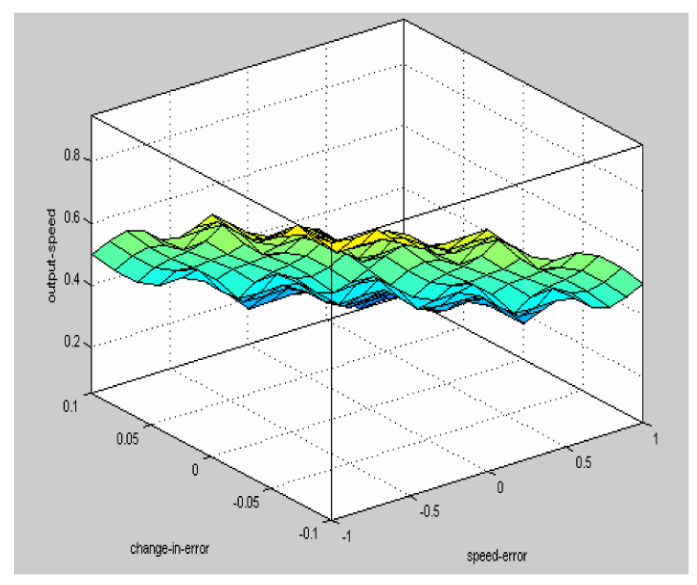

Figure 17. Surface view.
Table1. FLC rule table

\begin{tabular}{|c|c|c|c|c|c|c|c|c|}
\hline & \multicolumn{8}{|c|}{$\mathrm{e}$} \\
\hline \multirow{8}{*}{$y$} & & NL & $\mathrm{NM}$ & NS & ZR & $\mathrm{PS}$ & PM & PL \\
\hline & NL & $\mathrm{PL}$ & $\mathrm{PL}$ & PM & $\mathrm{PM}$ & PS & PS & $Z \mathbb{R}$ \\
\hline & $\mathrm{NM}$ & $\mathrm{PL}$ & $\mathrm{PM}$ & $\mathrm{PM}$ & PS & DS & $2 R$ & NS \\
\hline & NS & PM & $\mathrm{PM}$ & PS & PS & $\mathrm{ZR}$ & NS & NS \\
\hline & ZR & $\mathrm{PM}$ & PS & $\mathrm{PS}$ & $2 \mathrm{R}$ & NS & NS & $\mathrm{MM}$ \\
\hline & PS & PS & PS & $\mathrm{ZR}$ & NS & NS & $\mathrm{MM}$ & $\mathrm{MM}$ \\
\hline & PM & $\overline{P S}$ & $\overline{\mathrm{ZR}}$ & $\mathrm{NS}$ & NS & $\mathrm{MM}$ & $\mathrm{MM}$ & $\mathrm{NL}$ \\
\hline & PL & $2 \mathrm{R}$ & NS & NS & $\mathrm{MM}$ & $\mathrm{MM}$ & $\mathrm{NL}$ & $\mathrm{NL}$ \\
\hline
\end{tabular}

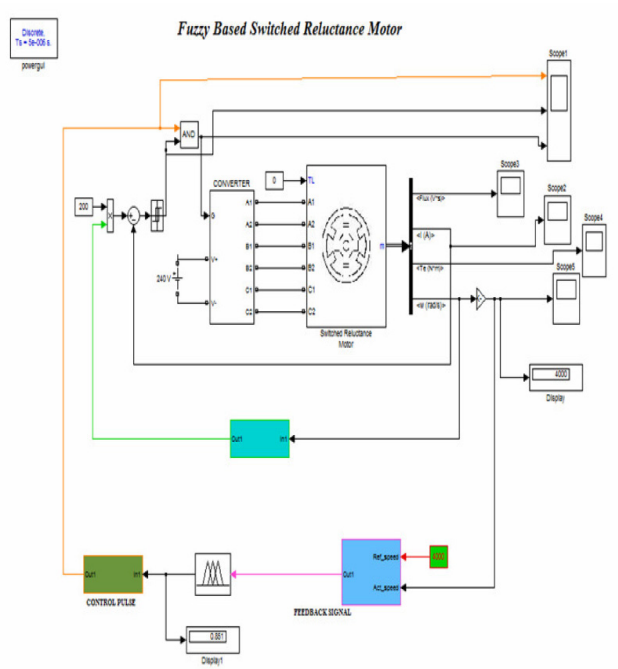

Figure 18. Simulink model using FLC.

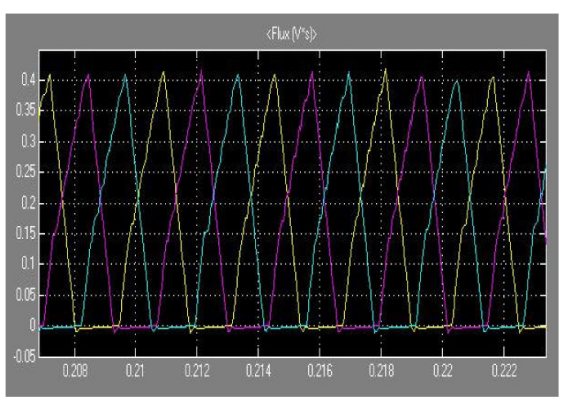

Figure 19. Output flux.

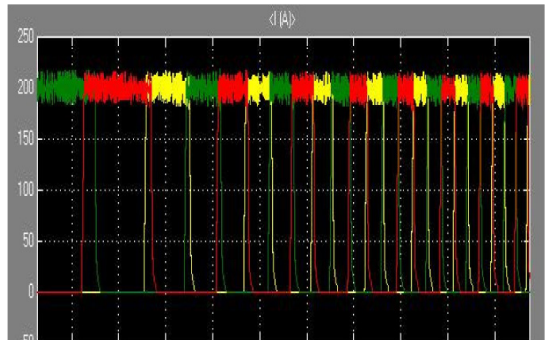

Figure 20. Output current. 


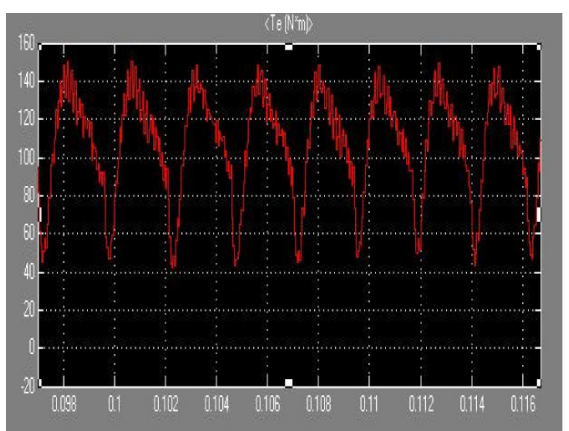

Figure 21. Output torque.

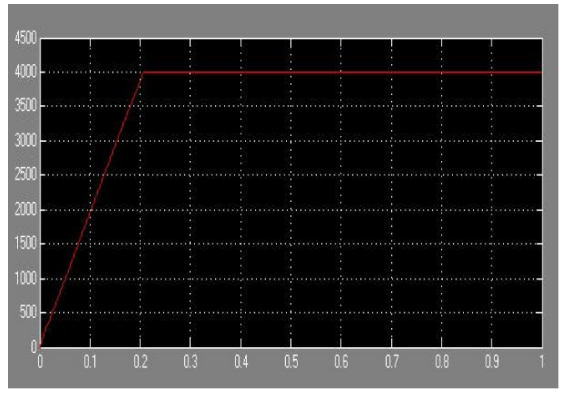

Figure 22. Speed.

If set speed is 4000 , the actual speed displayed is 4000 and the settling time is 0.2 . From speed waveform, it can be notified that the fuzzy logic controller enhances the speed regulation and it is a perfect speed tracking without overshoot.

The Table 2 shows speed comparison of proportional controller, proportional integral controller and fuzzy logic controller. For reference speed 4000, the following actual speed and settling time were obtained.

\section{Conclusions}

Thus the SRM dynamic performance is forecasted and by using MATLAB/simulink the model is simulated. SRM has been designed and implemented for its speed control by using P, PI controller and AI based fuzzy logic controller. We can conclude from the simulation results that when compared with P \& PI controller, the fuzzy Logic Controller meet the required output. This paper presents a fuzzy logic controller to ensure excellent reference tracking of switched reluctance motor drives. The fuzzy logic controller gives a perfect speed tracking without overshoot and enchances the speed regulation. The SRM response when controlled by
Table 2. Comparison of speed controllers

\begin{tabular}{lcc}
\hline Controllers & $\begin{array}{c}\text { Reference Speed } \\
\text { (Speed in rpm) }\end{array}$ & Settling Time \\
\hline P Controller & 4003 & $0.3 \mathrm{~S}$ \\
PI Controller & 3999 & $2 \mathrm{~S}$ \\
Fuzzy Logic & 4000 & $0.2 \mathrm{~S}$ \\
Controller & & \\
\hline
\end{tabular}

FLC is more advantaged than the conventional P\& PI controller.

\section{References}

1. Susitra D, Jebaseeli EAE, Paramasivam S. Switched reluctance generator - modeling, design, simulation, analysis and control -a comprehensive review. Int J Comput Appl. 2010; 1(210):975-8887.

2. Susitra D., Paramasivam S. Non-linear flux linkage modeling of switched reluctance machine using MVNLR and ANFIS. Journal of Intelligent and Fuzzy Systems. 2014; 26(2):759-768.

3. Susitra D, Paramasivam S. Rotor position estimation for a switched reluctance machine from phase flux linkage. IOSR-JEEE. 2012 Nov-Dec; 3(2):7.

4. Susitra D, Paramasivam S. Non-linear inductance modelling of switched reluctance machine using multivariate non- linear regression technique and adaptive neuro fuzzy inference system. CiiT International Journal of Artificial Intelligent Systems and Machine Learning. 2011 Jun; 3(6).

5. Ramya A, Dhivya G, Bharathi PD, Dhyaneshwaran R, Ramakrishnan P. Comparative study of speed control of $8 / 6$ switched reluctance motor using pi and fuzzy logic controller. IJRTE; 2012.

6. Rodrigues MG, Suemitsu WI, Branco P, Dente JA, Rolim LGB. Fuzzy logic control of a switched reluctance motor. Proceedings of the IEEE International Symposium. 1997; 2:527-31.

7. Wadnerkar VS, Das GTR, Rajkumar AD. Performance analysis of switched reluctance motor; design, modeling and simulation of $8 / 6$ switched reluctance motor. J Theor Appl Inform Tech. 2005-2008.

8. Hany GMH, Hasanien M. Speed control of switched reluctance motor based on fuzzy logic controller. Proceedings of the 14th International Middle East Power Systems Conference (MEPCON'10), Cairo University, Egypt, 2010 Dec 19-21, Paper ID 166.

9. Krishnan R. Switched reluctance motor drives: modelling, Simulation, analysis, design and applications, CRC Press; 2001. 